Bangladesh J. Genet Pl. Breed., 21(1): 49-54, 2008

\title{
GENETIC DIVERSITY IN LOCAL RAINFED LOWLAND RICE (Oryza sativa L.) IN BANGLADESH
}

\author{
M. Khalequzzaman, M. Z. Islam, Khaleda Akter and M. K. Bashar \\ Genetic Resources and Seed Division \\ Bangladesh Rice Research Institute \\ Gazipur 1701, Bangladesh
}

\begin{abstract}
Genetic diversity of 40 traditional Bangladeshi rice genotypes was studied under rainfed lowland condition through Mahalanobis $\mathrm{D}^{2}$ statistic for grain yield and yield contributing characters. The genotypes were grouped into six clusters. The inter cluster distances were higher than the intra cluster distances indicating wider genetic diversity among the genotypes of different clusters. The intra cluster distances were lower in all the cases reflecting homogeneity of the genotypes within the clusters. The cluster VI contained the highest number of genotypes (12) and the cluster IV contained the lowest (2). The highest intra cluster distance was noticed for the cluster VI and the lowest for cluster IV. The highest inter cluster distance was observed between cluster III and IV followed by clusters IV and V, clusters I and IV, clusters IV and VI and the lowest between clusters II and VI. Regarding inter cluster distance, cluster IV showed high genetic distance from all other four clusters except cluster II. The genotypes from cluster IV could be hybridized with the genotypes of any of the four clusters for producing transgressive segregants. Days to flowering, duration and spikelets/panicle were mainly responsible for genetic divergence while considering mean values. Though filled grains/panicle and flag leaf area are the most positive contributors based on the latent vectors. The highest cluster means for yield and 1000 grain weight and other $2^{\text {nd }}$ highest four yield contributing characters (viz. plant height, days to maturity, panicle length and flag leaf area) were obtained from cluster III. The highest flag leaf area, plant height, panicle length, filled grains per panicle and grain length were found in cluster V. Cluster IV had the lowest mean for yield and other moderate to low yield contributing characters. Therefore more emphasis should be given on cluster V and III for selecting genotypes as parents for crossing with the genotypes of cluster IV which would be used to produce new recombinants with desired traits.
\end{abstract}

Key words: Genetic diversity, $\mathrm{D}^{2}$ analysis, cluster analysis, rice (Oryza sativa $\mathrm{L}$ )

\section{INTRODUCTION}

Rice is considered as a major crop in Bangladesh as it constitutes $94.38 \%$ of the total food grain (rice \& wheat) production of 26.7 million metric tons (Anonymous, 2004). Rice is the staple food and ranks first position by production among cereals in Bangladesh. Although Bangladesh is now on the verge of attaining self sufficiency in cereal production, there is still a large gap between the production and demand. Among other ecosystem, rainfed lowland (transplanted aman) is the most suitable for growing rice in this country. 
Area under transplanted aman is the largest which is about 53\% of total rice land and contributes $45 \%$ of the total rice production (BBS 2001).

Genetic diversity is the extent of genetic variation existed among selected cultivars, breeding lines or species. The knowledge and degree of nature of divergence is useful in selection of the desirable parents for breeding program. With the development of advanced biometrical techniques such as multivariate analysis based on the Mahalanobis (1936) statistics, quantification of divergence among the biological population and assessing the relative contribution of different components to the total divergence at intra- and intercluster levels have now become possible. Such a study also permits to select the genetically diverse parents to obtain the desirable recombinant in the segregating generations upon crossing. Hybridization is a common practice for combining the desirable characters of two or more lines or varieties into a single variety. In several cases, the progenies become far superior to the parents in vigor i.e. hybrid vigor or heterosis. Inclusion of more diverse parents (within a limit) is believed to increase the changes for obtaining stronger heterosis and gives broad spectrum of variability in segregating generations (Joshi and Dhawan, 1966; Ananda and Murty, 1968). In addition, crossing in moderately diverse parents also showed maximum heterosis (Chauhan and Singh, 1982). The necessity of principal component analysis (PCA), principal coordinate analysis (PCO), non-hierarchical clustering and canonical vector analysis (CVA) for measuring the degree of divergence has been established by several investigators in rice and other crops (Selvakumar et al., 1989; De et al., 1988; Pathan et al., 1993).

There are more than 6000 rice germplasms have been preserved in BRRI genebank. But information on this aspect is scanty. The present study was, therefore undertaken to assess the extent of genetic diversity in 40 traditional rice germplasms. This will help in classifying those into clusters to select varieties as prospective parents to develop transgressive segregants.

\section{MATERIALS AND METHODS}

Forty rice genotypes selected from the germplasm bank of Bangladesh Rice Research Institute (BRRI), Gazipur were grown during rainfed lowland condition (T. Aman) in 2005. The trial was conducted in a randomized complete block design with three replications. Thirty days-old seedlings from each entry were transplanted using single seedling per hill in $2.4 \mathrm{~m}^{2}$ plot following $25 \mathrm{~cm}$ and $15 \mathrm{~cm}$ space between rows and plants, respectively. Fertilizers were applied @ 60:60:40:12 kg N, P, K and S per hectare. All the fertilizers except $\mathrm{N}$ were applied at final land preparation. Nitrogen was applied in three equal splits, at 15 days after transplanting (DAT), at 35 DAT and just before flowering. Intercultural operations and pest control measures were done as and when necessary. At maturity, grain yield (g/hill) was taken and adjusted at $14 \%$ moisture level. Ten plants from each entry were randomly selected for recording data on plant height $(\mathrm{cm})$, days to flowering, days to maturity, panicle length $(\mathrm{cm})$, panicle number/plant, grain length $(\mathrm{mm})$, grain breadth $(\mathrm{mm}), 1000$ grain weight $(\mathrm{g})$, grains/panicle, harvest index (HI), flag leaf area $\left(\mathrm{cm}^{2}\right)$ and yield/ plant. Flag leaf area was calculated according to Gomez (1983). The data were analyzed following principal component analysis (PCA) and Mahalanobis's (1936) generalized distance $\left(\mathrm{D}^{2}\right)$ extended by Rao (1952). Intra and inter cluster distances were calculated by the methods of Singh and Chaudhury (1985). All statistical analyses were carried out using Genstat 513. 


\section{RESULTS AND DISCUSSIONS}

Analysis of variance showed significant differences among the 40 genotypes for all the ten characters under study indicating the presence of notable genetic variability among the genotypes. The principal component analysis showed that the first two components accounted for $83.83 \%$ of the total variation.

Based on the degree of divergence forty genotypes were grouped into six clusters on the basis of cluster analysis (Table 1). Maximum 12 entries were grouped into the cluster VI, followed by 8 in clusters II and III, and six in cluster I. The cluster IV contained the lowest (2) number of genotypes.

Table 1. Distribution of 40 rice genotypes in different clusters grown in T Aman 2006

\begin{tabular}{|c|c|c|c|}
\hline $\begin{array}{l}\text { Cluster } \\
\text { No. }\end{array}$ & $\begin{array}{l}\text { BRRI Accession no. of } \\
\text { Genotypes with serial no in } \\
\text { parenthesis. }\end{array}$ & $\begin{array}{l}\text { No. of } \\
\text { Population }\end{array}$ & Genotypes \\
\hline I & $\begin{array}{l}32(3), 65(5), 69(6), 220(10), \\
1059(14), 1456(24)\end{array}$ & 6 & $\begin{array}{l}\text { Joria ropa Aman, Bhasha, Nayaraj Savar, } \\
\text { Raimihi, Kaku, Khama }\end{array}$ \\
\hline II & $\begin{array}{l}10(1), 73(8), \quad 34(9), 1043(12), \\
1417(22), 1430(23), 2399(29), \\
2680(36)\end{array}$ & 8 & $\begin{array}{l}\text { Ghatt bhada, PL-3, Jossobalam, Bota, } \\
\text { Paijong, Balam, Gota Bazal, Sadajira fine - } \\
261\end{array}$ \\
\hline III & $\begin{array}{l}53(4), \quad 1047(13), \quad 1074(16), \\
1104(17), 1515(25), 1516(26), \\
1588(27), 2939(40)\end{array}$ & 8 & $\begin{array}{l}\text { Gulapi, Kumra Goir,Bachoi Kolom, Lachya, } \\
\text { Dudmuna, Lotor, Kutiagrani, Awned TAPL- } \\
545\end{array}$ \\
\hline IV & 24(2), 1166(19) & 2 & Swarna, Baktulsi \\
\hline V & $\begin{array}{l}72(7), \quad 1600(28), \quad 2670(32), \\
2898(39)\end{array}$ & 4 & $\begin{array}{l}\text { PL-2, Binna Chupi, Sadajira fine-250, } \\
\text { Straw TAPL-500 }\end{array}$ \\
\hline VI & $\begin{array}{l}1039(11), 1069(15), 1115(18), \\
1231(20), 1412(21), 2650(30), \\
2667(31), 2671(33), 2675(34), \\
2679(35), 2681(37), 2683(38)\end{array}$ & 12 & $\begin{array}{l}\text { Lalmota, Salkole(2), Munur, Indra Sail, } \\
\text { Gainda, Sadajirafine TAPL-230, Sadajira } \\
\text { fine-247, Sadajira fine-2501, Sadajira fine- } \\
\text { 255, Sadajira fine-260, Sadajira fine-262, } \\
\text { Sadajira fine-264 }\end{array}$ \\
\hline
\end{tabular}

Intra and inter cluster distance are presented in Table 2. The inter cluster distances in almost all of the cases was larger than the intra cluster distance indicating that wider diversity was present among genotypes of distance groups. The intra cluster distances were low for all the six cluster with the range of 0.419 in cluster IV to 3.395 in cluster VI which indicated homogeneous nature of the genotypes within the clusters. These results were supported by the findings of Iftekharuddaula et al. (2002) in rice. The $\mathrm{D}^{2}$ values ranged from 2.27 to 13.551 and PCA scores also indicated a high degree of genetic diversity among the genotypes. Regarding inter cluster distance, cluster IV showed maximum genetic distance (13.55) from cluster III followed by cluster V (10.827), cluster I (10.354), cluster VI (8.763) and so on. It is obvious that in most of the cases cluster IV produceed the highest $\mathrm{D}^{2}$ values with all other clusters except cluster II suggesting wide diversity between them and the genotypes in these clusters could be used as parents in hybridization program for getting transgressive segregants (Saini and Kaiker, 1987). Moderate inter cluster distance was observed between cluster I and cluster V (7.992), followed by cluster II and cluster IV (6.793), cluster II and cluster III (6.784). The minimum inter cluster divergence was 
observed between cluster II and cluster VI (2.72) and cluster V and cluster VI (3.56) indicating that the genotypes of these clusters were genetically closed.

Table 2. Intra (bold) and inter cluster distances $\left(D^{2}\right)$ for 26 rice genotypes

\begin{tabular}{l|c|c|c|c|c|c}
\hline Clusters & I & II & III & IV & V & VI \\
\hline I & $\mathbf{1 . 3 4 9}$ & 4.952 & 5.235 & 10.354 & 7.992 & 5.499 \\
II & & $\mathbf{2 . 1 4 7}$ & 6.784 & 6.793 & 5.067 & 2.272 \\
III & & & $\mathbf{2 . 5 0 3}$ & 13.551 & 5.746 & 5.297 \\
IV & & & $\mathbf{0 . 4 1 9}$ & 10.827 & 8.763 \\
V & & & & $\mathbf{2 . 8 2 6}$ & 2.922 \\
& & & & & & $\mathbf{3 . 3 9 5}$ \\
\hline
\end{tabular}

Table 3. Cluster means for ten characters in T. Aman rice

\begin{tabular}{lcccccccc}
\hline Characters & I & II & III & IV & V & VI \\
\hline Plant height (cm) & 129.40 & 127.56 & 139.81 & 88.00 & 144.58 & 126.68 \\
Days to flowering & 98 & 103 & 113 & 107 & 109 & 115 \\
Days to maturity & 130 & 135 & 146 & 138 & 140 & 147 \\
Panicle length (cm) & 24.19 & 25.58 & 25.6 & 23.90 & 28.22 & 25.34 \\
No. of panicle/ hill & 12 & 13 & 12 & 10 & 11 & 12 \\
Filled grains/ panicle & 68 & 95 & 80 & 93 & 110 & 94 \\
Unfilled grains/ panicle & 26 & 35 & 12 & 36 & 19 & 19 \\
Grain length (mm) & 8.88 & 8.08 & 8.57 & 8.51 & 9.66 & 8.81 \\
Grain breadth (mm) & 3.00 & 2.78 & 3.32 & 2.98 & 2.83 & 2.83 \\
1000 grain weight $(\mathrm{g})$ & 23.35 & 18.71 & 26.38 & 21.93 & 22.40 & 21.04 \\
Flag leaf area (cm $\left.{ }^{2}\right)$ & 37.69 & 37.27 & 41.39 & 34.07 & 42.92 & 37.9 \\
Harvest Index & 0.22 & 0.26 & 0.19 & 0.24 & 0.19 & 0.22 \\
Yield (g/hill) & 4.41 & 7.17 & 9.37 & 6.41 & 9.12 & 8.21 \\
\hline
\end{tabular}

Days to flowering, growth duration and spikelets per panicle were mainly responsible for genetic divergence while considering mean values. The highest cluster means for yield and 1000-GW and other $2^{\text {nd }}$ highest four yield contributing characters (plant height, growth duration, panicle length and flag leaf area) were obtained from cluster III (Table 3). The highest flag leaf area, plant height, panicle length, filled grains per panicle and grain length were found in cluster $\mathrm{V}$ while the lowest mean value for yield and other low to moderate mean value for yield contributing characters were found in cluster I. Short duration, lower filled grains/ panicle and low yielding ( $\mathrm{t} / \mathrm{ha}$ ) varieties were clubbed into cluster I, whereas dwarf stature, lower panicle number, lower flag leaf area and also low yielding varieties (Swarna and Baktulsi) were clubbed into cluster IV. Maximum good characters were accumulated in cluster $\mathrm{V}$ and as a result higher yield $(9.12 \mathrm{~g} / \mathrm{hill})$ was also obtained in this cluster. But it was interesting that in most of the cases cluster IV could produced highest $\mathrm{D}^{2}$ values with all other clusters except cluster II. So they can be used in hybridization program to produce higher yielding genotypes. 
Table 4. Relative contributions of the ten characters to the total divergence in T. Aman rice

\begin{tabular}{lcc}
\hline Trait & Vector I & Vector II \\
\hline Plant height $(\mathrm{cm})$ & -0.2712 & -0.1115 \\
Days to flowering & -0.3641 & 0.3664 \\
Duration & -0.3730 & 0.3510 \\
Panicle length (cm) & -0.2152 & 0.0970 \\
No. of panicle/ hill & 0.1048 & -0.0083 \\
Filled grains/ panicle & 0.0095 & 0.4433 \\
Sterile spikelets/ panicle & 0.3462 & -0.1970 \\
Grain length (mm) & -0.2543 & -0.1897 \\
Grain breadth (mm) & -0.2998 & -0.3809 \\
1000 grain weight & -0.3651 & -0.4051 \\
Flag leaf area (cm) & -0.2724 & -0.2491 \\
Harvest index & 0.2201 & 0.0566 \\
Yield (t/ha) & -0.2589 & 0.2736 \\
\hline
\end{tabular}

Joshi and Dhawan (1966) reported that inclusion of more diverse parents (within a limit) is believed to increase the changes for obtaining stronger heterosis and gives broad spectrum of variability in segregating generations. Therefore, more emphasis should be given on cluster $\mathrm{V}$ and III for selecting genotypes as parents for crossing with the genotypes of cluster IV which may produce new recombinants with desired traits Cluster II had the highest cluster mean value for harvest index and also unfilled grains per panicle which had negative effect on mean value of yield. The longest durated and lower unfilled type plants were constellated in cluster VI. It was also noticeable that yield performance in six clusters was low and less variable. Variations were comparatively high in respect of their yield. From the above discussion it can be concluded that all these $\mathrm{T}$ Aman varieties are genetically distant from each other.

Contributions of the characters towards divergence are presented in Table 4. The canonical variate analysis revealed that the vectors (Vector I and II) for only filled grains/panicle and harvest index were positive. Such results indicated that these two characters contributed maximum towards divergence. It is interesting that the greater divergence in the present materials due to these two characters will offer a good scope for improvement of yield thorough rational selection of parents for producing heterotic rice hybrids.

It is assumed that, maximum amount of heterosis will be manifested in cross combinations involving the parents belonging to most divergent clusters. However, for a practical plant breeder, the objective is not only high heterosis but also to achieve high level of production and reducing the life duration. In the present study the maximum distances existed between cluster III and cluster IV. However, considering the yield, filled grains number and growth duration, crosses involving cluster $\mathrm{V}$ and cluster I may exhibit high heterosis for earliness and yield. Similarly cluster IV might be crossed with cluster III to get higher grain yield. Mian and Bahl (1989) reported that the parents separated by $\mathrm{D}^{2}$ values of 
medium magnitude generally showed higher heterosis in chickpea. Keeping this view in mind, it appears that the crosses between the genotypes/parents belonging to the cluster VI with that of cluster I and cluster V and cluster I or IV would exhibit high heterosis as well as higher level of yield potential. So based on this result, the genotypes under cluster I with cluster V and cluster IV with cluster III might be selected for future breeding program.

\section{REFERENCES}

Annonymous. 2004. Bangladesh Arthanaitic Sameekhkha, Ministry of Finance, Government of Bangladesh.

Anand, I. J. and B. R. Murty. 1968. Genetic divergence and hybrid performance in linseed. Indian J. Genet. and Plant Breeding. 28: 178-185.

BBS, 2001. Bangladesh Bureau of statistics. Ministry of Planning, Govt. of Bangladesh.

Chauhan, V. S. and B. B. Singh. 1982. Heterosis and genetic variability in relation to genetic divergence in soybean. Indian J. Genet.Pl. Breed. 42 (2): 324 - 328.

De, R. N., R. Seetharaman, M. K. Sinha and S. P. Banerjee. 1988. Genetic divergence in rice. Indian J. Pl. Breed. Genet. 48(2): 189-194.

Gomez, K. A. 1983. Techniques of yield experiments with rice. International Rice Research Institute, Philippines.

Iftekharuddaula, K. M., K. Akter, M. K. Bashar and M. R. Islam. 2002. Genetic parameters and cluster analysis of panicle traits in irrigated rice. Bangladesh J. Pl. Breed. Genet.15 (1): 49-55.

Joshi, A. B. and N. L. Dhawan. 1966. Genetic improvement of yield with special reference to self fertilizing crops. Indian J. Genet. and Plant Breeding. 26 A: 101-113.

Mahalanobis, P. C. 1936. On the generalized distance in Statistics. Proc. Natl. Inst. Sci., India 2: 49-55.

Mian, M. A. K. and P. N. Bahl. 1989. Genetic divergence and hybrid performance in chickpea. Indian J. Genet. 49 (1): 119-124.

Rao, C. R. 1952. Advanced Statistical method in biometrics research. John Wiley and sons. New York. p. 390.

Pathan, M. S., E. Haque, N. M. Miah and M. A. A. Miah. 1993. Genetic diversity in rice varieties released and recommended by BRRI. Bangladesh J. Bot. 22 (2): 161-166.

Saini, H. C. and U. S. Kaicker. 1987. Genetic diversity in opium poppy. Indian J. Genet. 291-296.

Selvakumar, K. S., G. Soundrapandian and A. Amirthadevarathinam. 1989. Genetic divergence for yield and yield components in cold tolerant rice. Madras Agril. J. 76(12): 688-694.

Singh, R. K. and B. D Chaudhury. 1985. Biometrical methods in quantitative genetic analysis. Kalayoni pulishers. New Delhi. p. 318. 